\title{
Anatomia descritiva do membro torácico do coelho (Oryctolagus cuniculus): revisão bibliográfica e atualização anatômica
}

\author{
Descriptive anatomy of forelimb of the rabbit (Oryctolagus cuniculus): \\ bibliographic review and anatomical update
}

Kassy Gomes da Silva (D)*, Ubirajara lobe Tasqueti (D), Cristina Santos Sotomaior (D)

Pontifícia Universidade Católica do Paraná (PUCPR), Curitiba, PR, Brasil

\section{Resumo}

O coelho doméstico (Oryctolagus cuniculus) é um mamífero herbívoro com importância na produção de carne, como animal de estimação e como modelo experimental. Conhecer a anatomia da espécie, com suas particularidades, é essencial para quem trabalha com ela. No entanto, o material bibliográfico disponível pode ser antigo ou de difícil acesso pelo estudante ou profissional. Atualmente, com a evolução dos métodos de imagem diagnóstica, as estruturas anatômicas estudadas podem ser observadas com maior detalhamento. Dessa forma, esta revisão de literatura buscou disponibilizar informações sobre a osteologia, miologia, vascularização e inervação do membro torácico do coelho, com atualização da nomenclatura com a Nômina Anatômica Veterinária de 2017.

Palavras-chave: Sistema nervoso. Miologia. Morfologia. Osteologia.

* Autor correspondente: kgomes13@hotmail.com Submetido: 19 jun 2019 | Aprovado: 6 jan 2020

\begin{abstract}
The domestic rabbit (Oryctolagus cuniculus) is an herbivorous mammal with importance in meat production, as a pet and as an experimental model. Know an anatomy of the specie, with its particularities, is essential to whom work with it. However, the available material for study may be old or difficult to access by the student or professional. Nowadays, with the diagnostic imaging methods evolution, the studied anatomical structures can be observed in greater detail. Thus, the literature review sought information on osteology, myology, vascularization and innervation of the forelimb of the rabbit, with the update of the nomenclature with Nomina Anatomica Veterinaria of 2017.
\end{abstract}

Keywords: Nervous system. Myology. Morphology. Osteology. 


\section{Introdução}

No Brasil, o coelho teve um crescimento de popularidade como animal de estimação nos últimos anos (Machado, 2015), além de ser uma fonte de proteína animal (Lebas et al.,1997) e de ter um importante papel como modelo animal na experimentação (Burkholder et al., 2012). Tanto para uso clínico como experimental, o conhecimento sobre a anatomia da espécie fazse necessário para a compreensão de processos fisiológicos e patológicos.

Artigos sobre a anatomia do coelho abordam, porvezes, um processo patológico ou uma alteração específica, dividindo grandes regiões anatômicas em pontos específicos, dificultando o estudo geral da região anatômica investigada (Doschak et al., 2001; Grumet et al., 2009). Referências que abordam uma determinada região anatômica inteira de uma forma mais detalhada são, em sua maioria, antigas (Crabb, 1931; Bensley e Craigie, 1948). Por consequência, são desatualizadas em relação à atual Nômina Anatômica Veterinária (ICVGAM, 2017) ou de difícil acesso ao público, por serem escritas em língua estrangeira (Krause,1868) ou distribuídas somente por via impressa (Barone, 1986). O membro torácico do coelho tem sido utilizado como modelo experimental em estudos médicos (Baumann et al., 2015; Buettmann e Silva, 2016), além de fazer parte da rotina veterinária, como em casos de processos patológicos e traumas ortopédicos que podem acometer a região (Varga, 2014).

Assim, teve-se por objetivo realizar uma revisão de literatura, com atualização da nomenclatura de acordo com a Nômina Anatômica Veterinária de 2017 (ICVGAM, 2017), da osteologia, miologia, vascularização e inervação do membro torácico do coelho doméstico (Oryctolagus cuniculus).

O projeto foi aprovado pela Comissão de Ética em Pesquisa no Uso de Animais (CEUA) sob número $01603-1^{\text {a }}$ versão.

\section{Osteologia do membro anterior (torácico)}

O esqueleto do membro torácico é dividido em duas porções: a proximal (escápula e clavícula) e a distal (extremidade livre). A escápula e a clavícula formam, juntas, a cintura escapular. Esta é constituída com o maior suporte vindo das musculaturas anexas a ela, e é diretamente ligada ao esqueleto axial somente através do ligamento esternoclavicular (Bensley e Craigie, 1948; Sohn e Couto, 2012). A extremidade livre do membro é dividida em segmentos proximal (composto pelo úmero), médio (rádio e ulna) e distal (ossos sesamóides acessórios, carpo, metacarpo e falanges) (Bensley e Craigie, 1948).

\section{Escápula}

A escápula (Scapula) é uma placa óssea alongada em formato triangular que se encontra naturalmente na face lateral da região cranial do tórax, com o ápice voltado para o sentido distal e cranial (Bensley e Craigie, 1948; Barone, 1986). Possui três bordas: a cranial (Margo cranialis), voltada ao occipital (pescoço) e ligeiramente mais convexa; a dorsal (Margo dorsalis), em direção à coluna vertebral; e a caudal (Margo caudalis), mais retilínea e espessa, em direção à axila (Bensley e Craigie, 1948; Barone, 1986; ICVGAM, 2017). Na margem dorsal, encontra-se uma forte cartilagem escapular (Cartilago scapulae) (Barone, 1986; Popesko, 1997). Os ângulos correspondentes são o cranial (Angulus cranialis), caudal (Angulus caudalis) e lateral (Angulus ventralis) (Bensley e Craigie, 1948; ICVGAM, 2017). A superfície lateral (Fascies lateralis) possui uma robusta placa óssea, a espinha da escápula (Spina scapulae), que se origina do osso em cerca de dois terços de sua extensão e termina ventralmente em uma projeção livre, o acrômio (Acromion). A margem caudal do acrômio tem um processo voltado caudalmente, o processo hamato (Processus hamatus) (Bensley e Craigie, 1948; Callou, 1997; ICVGAM, 2017). A extremidade caudal e dorsal ao processo hamato é chamada de processo suprahamato (Processus suprahamatus), que é um processo relativamente longo, de 10 a 12 milímetros (Figura 1). Era conhecido como metacrômio (Barone, 1986; Popesko, 1997; Grumet et al., 2009).

A superfície lateral da escápula é dividida em duas áreas para fixação muscular. Uma delas, a fossa supraespinhosa (Fossa supraspinata), 
encontra-se cranial à espinha, e a outra, a fossa infraespinhosa (Fossa infraspinata), possui o dobro da largura da fossa supraespinhosa e está caudal à espinha da escápula (Bensley e Craigie, 1948; Barone, 1986). A superfície medial (Fascies costalis) apresenta uma única larga depressão, a fossa subescapular (Fossa subscapularis), que tem formato triangular e ocupa praticamente toda essa superfície (Bensley e Craigie, 1948; Barone, 1986). A fossa subescapular delimita a face serrátil (Facies serrata), uma superfície rugosa dorsal à fossa (König e Liebich, 2016). O ápice ou ângulo lateral da escápula (cabeça da escápula) é maior do que o colo da escápula (Collum scapulae), que o conecta com o corpo do osso. Possui uma depressão côncava, a cavidade glenoidal (Cavitas glenoidalis), para articulação com o úmero (Figura 1). A face articular também é formado pelo tubérculo supraglenoidal (Tuberculum supraglenoidale) (Callou, 1997) e é suportada principalmente pela borda axilar do osso, mas também se estende à porção cranial com uma projeção saliente, o processo coracóide (Processus coracoideus), que é forte e longo, ligeiramente encurvado (Bensley e Craigie, 1948; Barone, 1986; Callou, 1997). Esse possui uma projeção cega, semelhante a um gancho, na superfície medial do osso (Bensley e Craigie, 1948). Na porção caudal ao tubérculo supraglenoidal, observa-se o tubérculo infraglenoidal (Tuberculum infraglenoidale) (Grumet et al., 2009; ICVGAM, 2017).

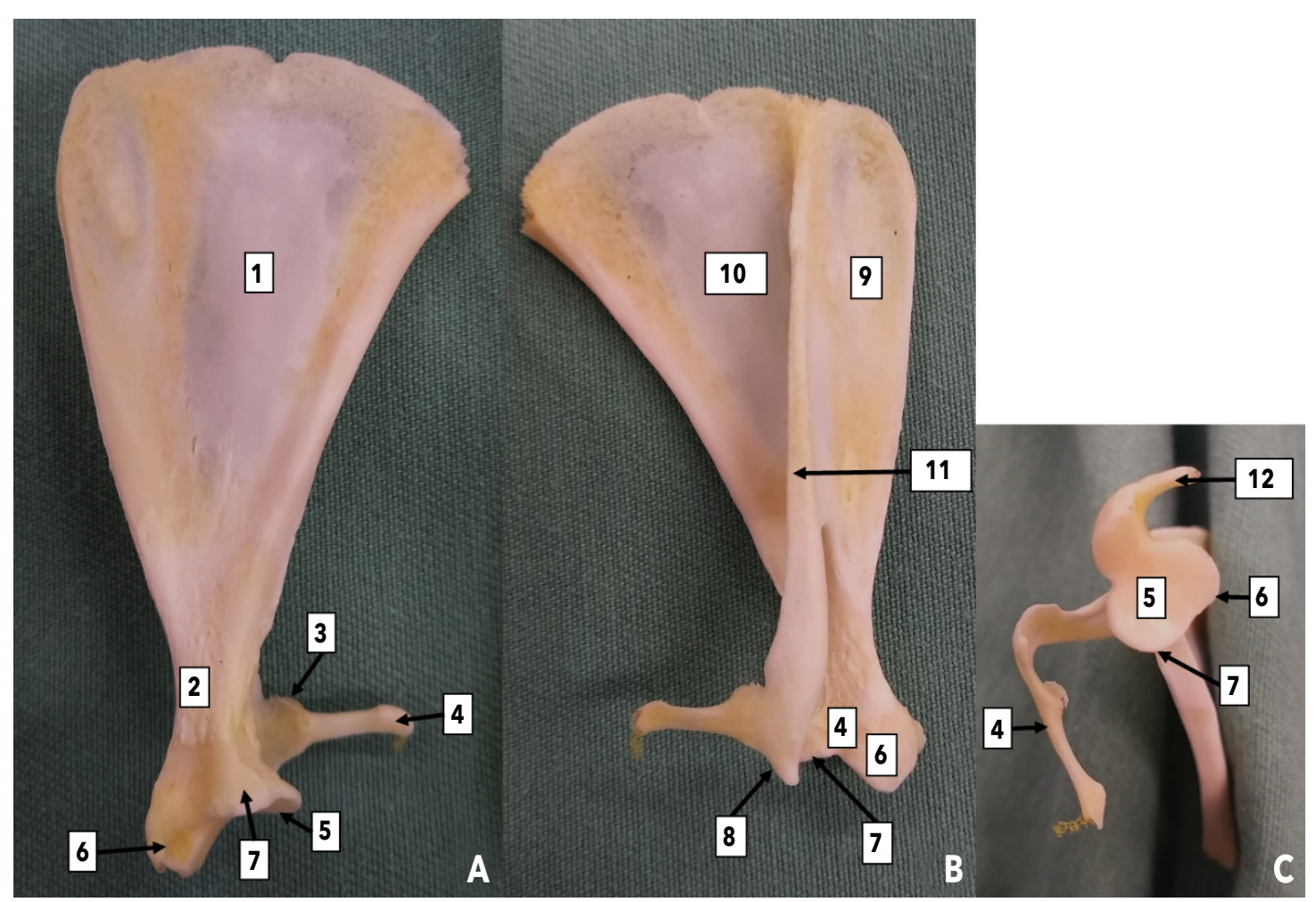

Figura 1 - Escápula de coelho. A - Vista medial. B - Vista lateral. C - Vista ventral. 1 - Fossa subescapular; 2 - Colo da escápula; 3 - acrômio; 4 - Processo suprahamato; 5 - Cavidade glenoidal; 6 - Tubérculo supraglenoidal; 7 - Tubérculo infraglenoidal; 8 - processo hamato; 9 - Fossa supraespinhosa; 10 - Fossa infraespinhosa; 11 - Espinha da escápula; 12 - Processo coracóide. 


\section{Clavícula}

A clavícula (Clavicula) é desenvolvida de forma imperfeita no coelho, consistindo de uma haste óssea delgada e curva, com média de 15 a 20 milímetros, inclinada pela cartilagem que fica entre o manúbrio esternal e a cabeça do úmero (Bensley e Craigie, 1948; Barone, 1986). É fixada medialmente pelo ligamento esternoclavicular e lateralmente por um ligamento acromioclavicular e um delgado ligamento coracoclavicular, todos os três muito alongados. As medidas desses ligamentos são $20 \mathrm{~cm}, 35 \mathrm{~mm}$ e $25 \mathrm{~mm}$ de comprimento, respectivamente (Sandstrom e Saltzman, 1944; Bensley e Craigie, 1948). O ligamento acromioclavicular liga a superfície cranial da extremidade lateral da clavícula ao processo hamato da escápula. O ligamento coracoclavicular conecta a superfície caudal da extremidade lateral da clavícula ao processo coracóide da escápula. O ligamento esternoclavicular estendese da superfície caudal da extremidade medial da clavícula à superfície dorsal do manúbrio (Sandstrom e Saltzman, 1944).

\section{Úmero}

O osso úmero (Humerus) é composto pela epífise proximal, corpo e epífise distal. $\mathrm{Na}$ epífise proximal, encontra-se, na face medial, uma projeção suave e convexa, a cabeça do úmero (Caput humeri), que se articula com a escápula (Figura 2). Imediatamente cranial à cabeça, observa-se uma pequena elevação, que corresponde à tuberosidade medial ou tubérculo menor (Tuberculum minus) e é separado por um sulco longitudinal, o sulco intertubercular (Sulcus intertubercularis), de uma elevação lateral maior, o tubérculo maior (Tuberculum majus) (Bensley e Craigie, 1948; Callou, 1997). Lateralmente, o tubérculo maior apresenta uma tuberosidade pequena em formato de gota d'água, nomeada Tuberositas teres minor. Além disso, é dividida em parte cranial (Pars cranialis), parte caudal (Pars caudalis) e crista (Crista tuberculi majoris) (Callou, 1997). A tuberosidade deltoide (Tuberositas deltoidea) inicia-se cranialmente à extremidade proximal, estende-se ao longo da diáfise e se prolonga distalmente como crista do úmero (Bensley e Craigie, 1948; Callou, 1997; König e Liebich, 2016). A crista do úmero (Crista humeri) é pouco distinta (Barone, 1986). O corpo do úmero (Corpus humeri) é dividido em quatro faces: cranial (Fascies cranialis), lateral (Fascies lateralis), acaudal (Fascies caudalis) e a medial (Fascies medialis) (ICVGAM, 2017).

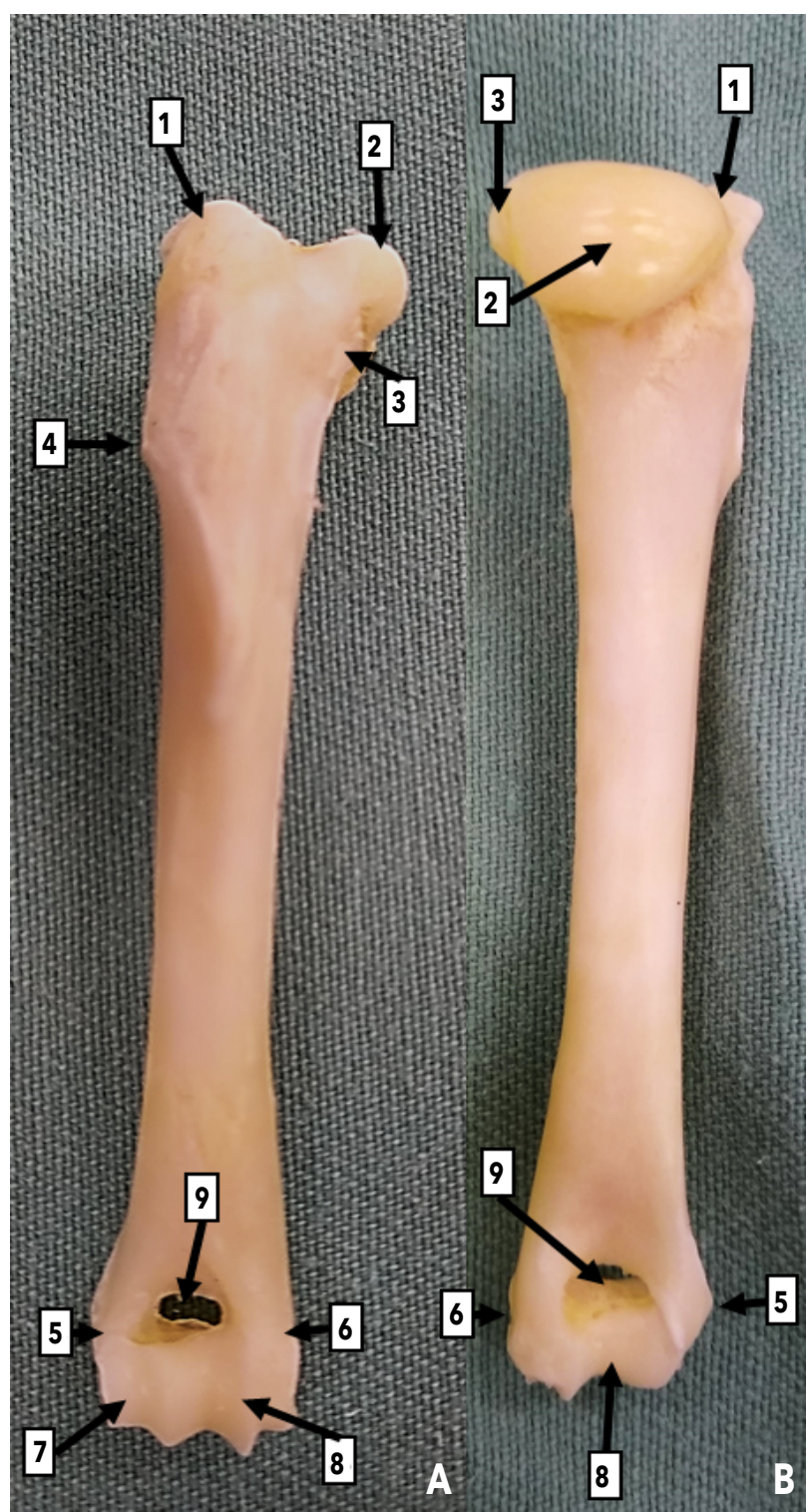

Figura 2 - Úmero de coelho. A - Vista cranial. B - Vista caudal. 1 - Tubérculo maior; 2 - Cabeça do úmero; 3- Tubérculo menor; 4 - Tuberosidade deltoide; 5 Epicôndilo lateral; 6 - Epicôndilo medial; 7 - Capítulo; 8 - Tróclea; 9 - Fossa do olécrano. 
A epífise distal é achatada na direção crâniocaudal e desprovida de forame supracondilar (Barone, 1986). O côndilo do úmero (Condylus humeri) encontra-se na epífise distal do úmero e possui uma superfície articular com bordas iguais e um sulco largo, a tróclea do úmero (Trochlea humeri), para articulação com o rádio e a ulna (Bensley e Craigie, 1948; Barone, 1986; König e Liebich, 2016). Lateralmente, encontra-se uma superfície menor, o capítulo (Capitulum humeri), que se articula com o rádio. Imediatamente dorsal à tróclea, as porções medial e lateral do osso são espessadas para formar duas áreas para fixação muscular, pouco marcadas (Bensley e Craigie, 1948; Barone, 1986; Callou, 1997). Um deles, o epicôndilo lateral (Epicondylus lateralis), é o ponto de origem para a maioria dos músculos extensores dorsais da mão, enquanto o epicôndilo medial (Epycondylus medialis) possui o mesmo fim para os músculos flexores da superfície ventral da mão (Bensley e Craigie, 1948; Callou, 1997). Os epicôndilos da extremidade do osso são profundos, de modo que as porções salientes do rádio e da ulna são recebidas em depressões da superfície quando o antebraço é flexionado ou estendido, respectivamente. Cranial a eles encontra-se a fossa radial (Fossa radialis), que é larga e profunda. Esta também é descrita como fossa coronóide (Barone, 1986) e comunica-se com a fossa do olecrano (Fossa olecrani), que se encontra caudal, através do forame supratroclear de pequeno diâmetro (Bensley e Craigie, 1948; Barone, 1986).

\section{Rádio}

O rádio (Radius) é o menor dos dois ossos do antebraço, com sua superfície dorsal convexa (Barone, 1986). Apresenta a epífise proximal com tendência lateral e epífise distal medial à ulna (Figura 3). A cabeça do rádio (Caput radii), localizada na epífise proximal, possui sua superfície articular correspondente à largura do úmero e possui articulação fixa com a ulna (Bensley e Craigie, 1948; Barone, 1986). A superfície articular é extensa, para contato com a tróclea e capítulo do úmero, encontrando-se nela a fóvea articular do rádio (Fovea capitis radii) (König e Liebich, 2016). A tuberosidade do rádio
(Tuberositas radii) encontra-se distal ao colo do rádio (Collum radii) (Barone, 1986). O corpo do rádio (Corpus radii) apresenta a face cranial (Facies cranialis) lisa (König e Liebich, 2016) e a face caudal (Facies caudalis) solidamente unida à ulna pelo ligamento interósseo do antebraço e, visto medialmente, é curvado em direção craniocaudal (Bensley e Craigie, 1948; Callou, 1997). Uma crista craniocaudal, acompanhada por uma fossa, forma parte da incisura da tróclea (Incisura trochlearis), sendo a outra parte constituída pela ulna. $\mathrm{Na}$ vista cranial, três sulcos profundos se localizam na extremidade distal da diáfise e correspondem às inserções dos tendões dos músculos extensores (Barone, 1986; Callou, 1997).

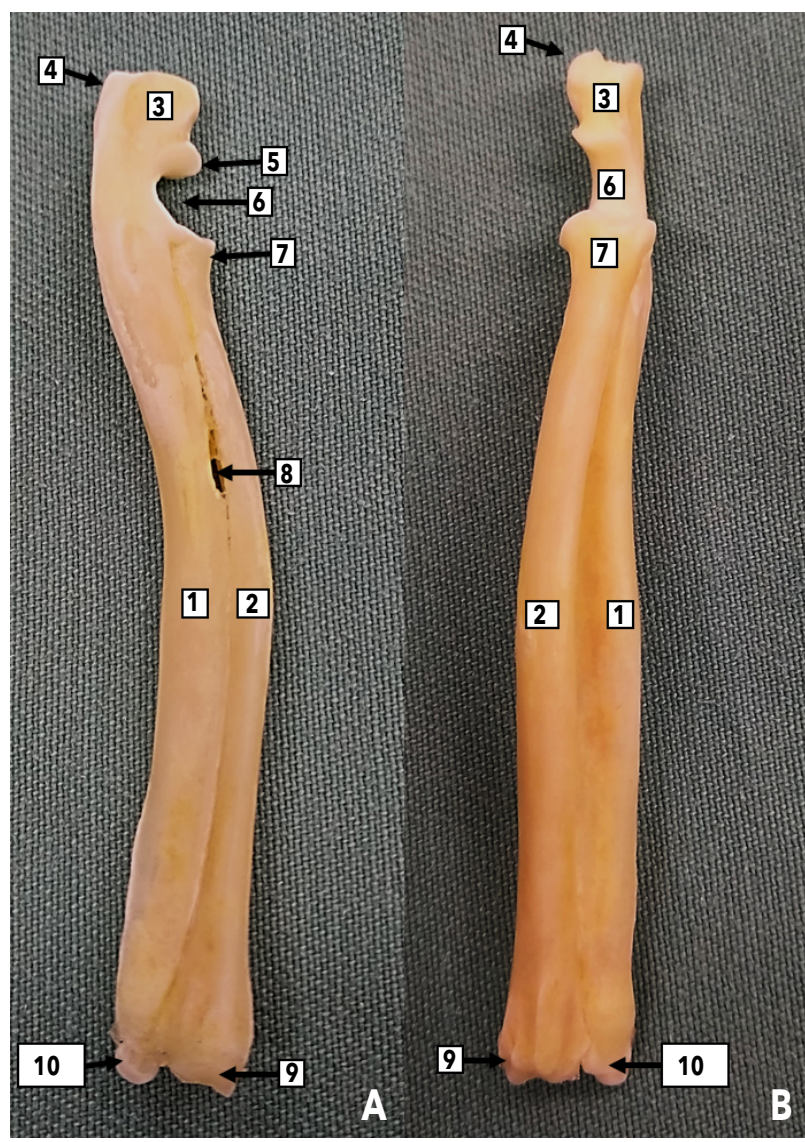

Figura 3 - Rádio e ulna do coelho. A - Vista lateral. B Vista craniocaudal. 1 - Ulnar; 2 - Rádio; 3 - Olécrano; 4 - Tuberosidade do olécrano; 5 - Processo ancôneo; 6 - Incisura semilunar; 7 - Cabeça do rádio; 8 - Espaço interósseo do antebraço; 9 - Tróclea do rádio; 10 Processo estilóide da ulna. 
A epífise distal é, em grande parte, formada pela tróclea (Trochlea radii), que é bem marcada em animais mais velhos. Possui uma superfície articular carpal sulcada (Facies articularis carpea) para articulação com os ossos carpo radial e carpo intermédio (Bensley e Craigie, 1948). A crista transversa (Crista transversa) está proximal à face articular do carpo do rádio (König e Liebich, 2016).

\section{Ulna}

A ulna (Ulna) é um osso em forma de "S", cujo corpo é achatado verticalmente, de modo que possui duas superfícies principais: cranial e caudal. A primeira, em conjunto com a superfície relacionada do rádio, tem a área de origem dos músculos extensores da mão, enquanto a segunda tem uma função semelhante relacionada aos músculos flexores (Bensley e Craigie, 1948).

A porção proximal da ulna é comprimida lateralmente. Possui uma depressão crescente, a incisura semilunar ou troclear (Incisura trochlearis), cuja superfície articular continua com a da porção medial da cabeça do rádio, e recebe a tróclea do úmero. Dorsal à incisura, o olécrano (Olecranon) (Figura 3) projeta o processo ancôneo (Processus anconaeus), o qual encaixa na extremidade distal do úmero (Silverman e Tell, 2005; König e Liebich, 2016). O olécrano é um processo forte para inserção dos músculos extensores (Bensley e Craigie, 1948). Na borda encontra-se a tuberosidade do olécrano (Tuber olecrani), que possui duas cristas, a lateral e a medial, separadas por um sulco longitudinal, como em carnívoros (Barone, 1986; Callou, 1997).

O corpo da ulna (Corpus ulnae) possui um diâmetro constante desde a extremidade proximal até a distal (Callou,1997) e na face cranial observase o espaço interósseo do antebraço (Spatium interosseum antebrachii) (König e Liebich, 2016). A extremidade distal do osso é formada por uma epífise (Caput ulnae) similar, porém maior que a do rádio, de formato triangular (Bensley e Craigie, 1948; Callou, 1997). É uma articulação imóvel com o rádio e sua ponta é formada pelo processo estiloide (Processus styloideus), pouco saliente, que se articula com o carpo (Bensley e Craigie, 1948; Barone, 1986).

\section{Carpo}

O carpo (Ossa carpi) é constituído por duas fileiras de ossos (Sohn e Couto, 2012). Seguindo de medial para lateral, na linha proximal, é composto pelos ossos carpo radial (Os carpi radiale), carpo intermédio (Os carpi intermedium), carpoulnar (Os carpi ulnare) e carpo acessório (Os carpi accessorium) (Figura 4) (Crabb, 1931; Bensley e Craigie, 1948; Barone, 1986; König e Liebich, 2016).

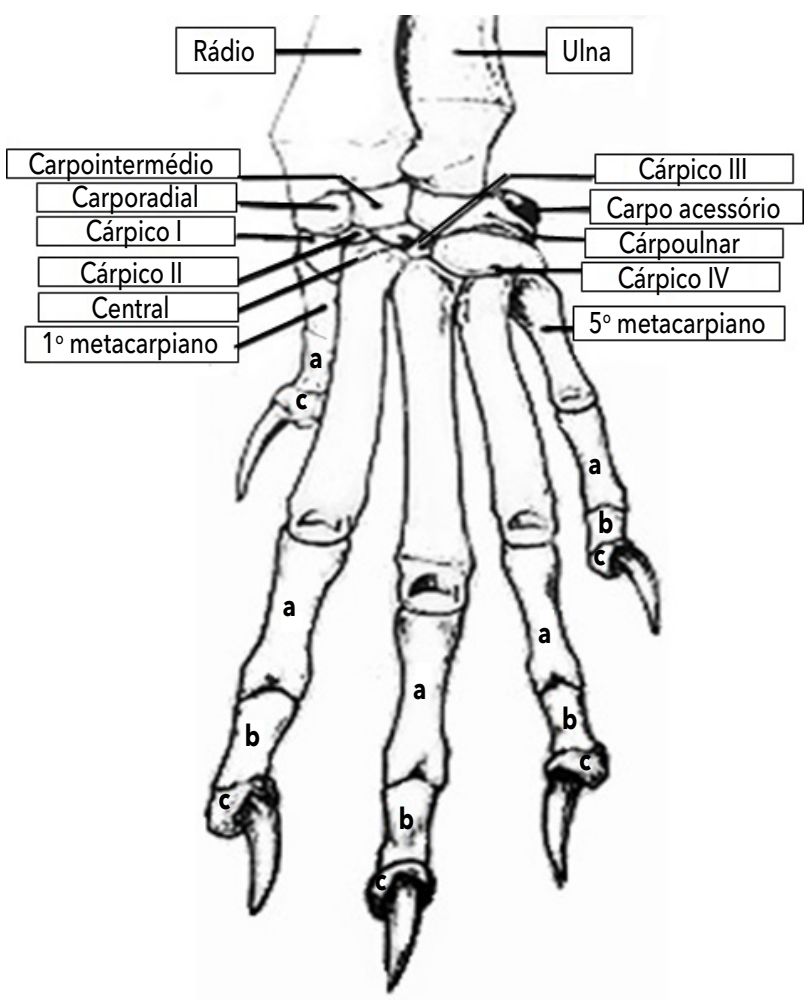

Figura 4 - Carpo, metacarpo e falanges do coelho. a falange proximal; b - falange média; c - falange distal. Adaptado de Barone (1986).

Os ossos do carpo tiveram diferentes nomenclaturas de acordo com o tempo, sendo a de König e Liebich (2016) a utilizada atualmente (Quadro 1). Os ossos carpo radial e carpo intermédio articulam-se com a extremidade distal do rádio. $O$ carpo ulnar articula-se com o processo estiloide da ulna. O carpo acessório encontra-se na superfície caudal/palmar da extremidade distal 
da ulna, articulando-se com o processo estiloide da ulna, e é pouco visto/invisível dorsalmente, sendo considerado um osso sesamóide anexado aos três ossos carpais proximais (Crabb, 1931; Bensley e Craigie, 1948; Barone, 1986). A linha distal contém, de medial para lateral, os ossos cárpico I (Os trapezium), cárpico II (Os trapezoideum), que é pequeno e articula-se em maior parte com o cárpico I, cárpico III (Os capitatum), que é pequeno e estreito, e cárpico IV (Os hamatum), que é o maior desses ossos. O primeiro, segundo e terceiro estão associados, respectivamente, com o primeiro, segundo e terceiro metacarpianos (Crabb, 1931; Bensley e Craigie, 1948; König e Liebich, 2016; ICVGAM, 2017). O osso central encontra-se na lateral da articulação, na base do segundo metacarpiano e interposto entre as fileiras proximais e distais (Crabb, 1931; Bensley e Craigie, 1948; Barone, 1986) e não é descrito na Nômina (ICVGAM, 2017). O osso cárpico IV é relativamente grande e está associado ao quarto e ao quinto metacarpiano, mas estende-se à articulação do terceiro, onde tende a substituir o osso cárpico III, que é reduzido (Crabb, 1931; Bensley e Craigie, 1948).

Quadro 1 - Nomenclatura dos ossos do carpo de acordo com diferentes autores

\begin{tabular}{|c|c|c|c|c|c|c|}
\hline \multicolumn{7}{|c|}{ Autores } \\
\hline \multirow{9}{*}{$\begin{array}{l}\text { 을 } \\
\text { 응 } \\
\text { 음 } \\
\text { ̌̆ }\end{array}$} & $\begin{array}{l}\text { Crabb } \\
(1931)\end{array}$ & $\begin{array}{c}\text { Bensley e Craigie } \\
\text { (1948) }\end{array}$ & $\begin{array}{l}\text { Whitehouse e Grove } \\
\qquad(1956)\end{array}$ & $\begin{array}{l}\text { Barone } \\
(1986)\end{array}$ & $\begin{array}{l}\text { König e Liebich } \\
\text { (2016) }\end{array}$ & $\begin{array}{l}\text { ICVGAM } \\
(2017)\end{array}$ \\
\hline & Navicular & Navicular & Escafóide ou radial & Escafóide ou radial & $\begin{array}{l}\text { Escafóide ou } \\
\text { carpo radial }\end{array}$ & $\begin{array}{c}\text { Os carpi radiale } \\
\text { [Os scaphoideum] }\end{array}$ \\
\hline & $\begin{array}{l}\text { Lunar } \\
\text { (lunate) }\end{array}$ & $\begin{array}{l}\text { Lunar } \\
\text { (lunate) }\end{array}$ & $\begin{array}{l}\text { Intermédio ou } \\
\text { semilunar }\end{array}$ & Lunar (lunatum) & $\begin{array}{l}\text { Semilunar ou } \\
\text { intermédio do carpo }\end{array}$ & $\begin{array}{c}\text { Os carpi intermedium } \\
\text { [Os lunatum] }\end{array}$ \\
\hline & Triquetral & Triquetral & Ulnar ou cuneiforme & Piramidal ou ulnar & $\begin{array}{l}\text { Piramidal ou } \\
\text { carpoulnar }\end{array}$ & $\begin{array}{l}\text { Os carpi ulnare } \\
\text { [Os triquetrum] }\end{array}$ \\
\hline & pisiforme & Pisiforme & Pisiforme & $\begin{array}{l}\text { Pisiforme ou aces- } \\
\text { sório }\end{array}$ & $\begin{array}{c}\text { Pisiforme ou } \\
\text { acessório do carpo }\end{array}$ & $\begin{array}{c}\text { Os carpi accessorium } \\
\text { [Os pisiforme] }\end{array}$ \\
\hline & Trapézio & $\begin{array}{l}\text { Grande metangular } \\
\text { (greater metangular) }\end{array}$ & Carpal I ou trapézio & Trapézio & $\begin{array}{l}\text { Trapézio ou } \\
1^{0} \text { osso carpal }\end{array}$ & $\begin{array}{c}\text { Os carpale I } \\
\text { [Os trapezium] }\end{array}$ \\
\hline & Trapezóide & $\begin{array}{l}\text { Pequeno metangular } \\
\text { (lesser metangular) }\end{array}$ & $\begin{array}{l}\text { Carpal II ou trape- } \\
\text { zóide }\end{array}$ & Trapezóide & $\begin{array}{l}\text { Trapezoide ou } \\
2^{\circ} \text { osso carpal }\end{array}$ & $\begin{array}{c}\text { Os carpale II } \\
\text { [Os trapezoideum] }\end{array}$ \\
\hline & $\begin{array}{c}\text { Grande } \\
\text { (magnum) }\end{array}$ & $\begin{array}{l}\text { Capitato } \\
\text { (capitate) }\end{array}$ & $\begin{array}{l}\text { Carpal III ou grande } \\
\text { (magnum) }\end{array}$ & $\begin{array}{l}\text { Capitato } \\
\text { (capitatum) }\end{array}$ & $\begin{array}{l}\text { Capitato ou } \\
3^{0} \text { osso carpal }\end{array}$ & $\begin{array}{l}\text { Os carpale III } \\
\text { [Os capitatum] }\end{array}$ \\
\hline & Unciforme & $\begin{array}{l}\text { Hamato } \\
\text { (hamate) }\end{array}$ & Unciforme & $\begin{array}{l}\text { Hamato } \\
\text { (hamatum) }\end{array}$ & $\begin{array}{l}\text { Hamato ou } \\
4^{0} \text { osso carpal }\end{array}$ & $\begin{array}{l}\text { Os carpale IV } \\
\text { [Os hamatum] }\end{array}$ \\
\hline
\end{tabular}

\section{Metacarpo}

metacarpo (Ossa metacarpalia) é formado por cinco ossos que servem de suporte para as falanges (Figura 4). Cada osso consiste em uma epífise proximal achatada, a base (Basis), corpo (Corpus) e epífise distal, a cabeça (Caput). A base possui uma face para articulação com o carpo (Facies articularis). O corpo apresenta a face palmar (Facies palmaris) e a face dorsal (Facies dorsalis), sendo observados palmare dorsalmente.
Os quatro ossos laterais normalmente são desenvolvidos, enquanto o primeiro é pequeno e encontra-se na superfície medial, pertencendo a um dígito reduzido (Bensley e Craigie, 1948). O terceiro metacarpiano é o mais comprido, com o segundo e quarto metacarpianos um pouco mais curtos. O quinto metacarpiano é menor e menos robusto do que o terceiro. $O$ primeiro metacarpiano possui um prolongamento na base que se estende até o osso carpo radial e é curto e espesso. $\mathrm{O}$ segundo metacarpiano possui 
uma extensão na base que alcança o terceiro metacarpiano e insinua-se entre o cárpico II e III (Barone, 1986). Cada metacarpo possui um par de ossos sesamóides anexados à articulação metacarpofalangeal no sentido palmar, que formam um sulco para passagem de um tendão flexor (Crabb, 1931; Sohn e Couto, 2012).

\section{Falanges}

Os ossos dos dígitos (Ossa digitorum manus) são distribuídos de acordo com a fórmula: 2, 3, 3, 3, 3 (Bensley e Craigie, 1948). As falanges são semelhantes às dos carnívoros (Barone, 1986). O primeiro dígito, na face medial, possui somente a falange proximal (Phalanx proximalis) e a falange distal (Phalanx distalis), sendo que os demais possuem a falange média (Phalanx media) entre as duas extremidades (Crabb, 1931). São similares ao formato dos metacarpianos, com exceção das falanges distais, que são comprimidas lateralmente, com formato pontiagudo e fissuradas em suas pontas para fixação das garras (Crabb, 1931; Bensley e Craigie, 1948). A falange proximal é dividida em base (Basis phalangis proximalis), corpo (Corpus phalangis proximalis) e cabeça (Caput phalangis proximalis) (Schaller, 2007). A mesma divisão ocorre para a falange média (Basis phalangis mediae, Corpus phalangis mediae e Caput phalangis mediae). A fóvea articular (Fovea articularis) está presente nas bases das falanges proximal e média para articulação com a extremidade distal dos ossos correspondentes. $\mathrm{Na}$ falange distal, a borda proximal é nomeada de margem coronal (Margo coronalis) e a Facies axialis corresponde à superfície axial do dígito (Schaller, 2007). A margem dorsal (Margo dorsalis) corresponde à vista dorsal do dígito, cuja extremidade final termina no ápice (Apex) da falange. A crista ungueal (Crista unguicularis) é uma elevação na base que cobre a raiz da garra. $O$ sulco ungueal (Sulcus unguicularis) contém a raiz da garra e próximo a este encontra-se o forame solar axial (Foramen soleare axiale) e, no lado contrário, o forame solar abaxial (Foramen soleare abaxiale). Na margem dorsal também se observa - processo ungueal (Processus unguicularis) (Schaller, 2007).

\section{Ossos sesamóides (Ossa sesamoidea)}

Desenvolvem-se nos ligamentos ou tendões dos músculos e associam-se com algumas articulações na superfície palmar. Ocorrem em pares transversos nas articulações metacarpofalangeanas e em pares lineares nas articulações entre as falanges proximal e média. O osso carpo acessório também é um sesamóide formado na inserção do tendão do músculo flexor carpo ulnar (Bensley e Craigie, 1948).

\section{Miologia do membro torácico}

\section{Ombro}

Os músculos serrátil ventral torácico e cervical (M. serratus ventralis thoracics, $M$. serratus ventralis cervicis) servem para a sustentação do tronco entre os dois membros torácicos e inserem-se na superfície medial da escápula de forma laminar na face serrátil e na cartilagem da escápula (Figura 5) (Popesko,1997; König e Liebich, 2016).

O músculo deltóide ( $M$. deltoideus) é um músculo triangular plano que cobre os dois terços inferiores da fossa infraespinhosa. É coberto com a fáscia escapular, pela qual se liga ao processo hamato. Sua extremidade distal atravessa o processo suprahamato abaixo e insere-se na crista deltóide do úmero (Cantier et al., 1968). Dividese em duas partes: acromial (Pars acromialis) e escapular (Pars scapularis) (Figura 5) (Bensley e Craigie, 1948; Barone, 1989). A parte acromial (antigamente chamada de músculo cleidobraquial ou parte clavicular do músculo deltóide - Popesko, 1997) tem origem no acrômio e inserção na porção distal da tuberosidade deltóide. A parte escapular origina-se na fáscia infraespinhosa (na fossa infraespinhosa) e sua porção muscular final forma uma curva sobre a porção dorsal do músculo infraespinhoso, deixando uma pequena porção triangular do último exposto. Sua inserção forma-se com a porção distal do músculo passando abaixo do processo suprahamato, que também serve como fixação, e é substituído na superfície lateral do úmero, abaixo do processo hamato, por um tendão fino, através do qual ele se insere ao lado da porção acromial (Bensley e Craigie, 1948; Barone, 1989). 


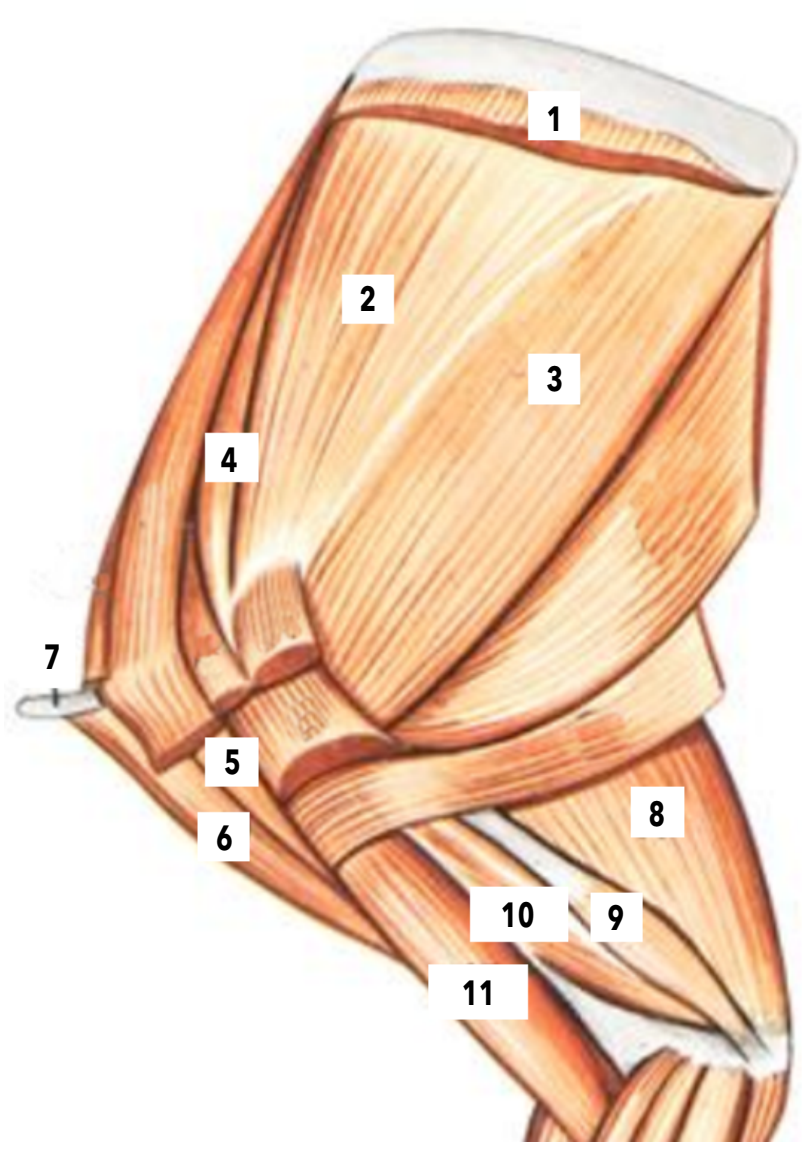

Figura 5 - Musculatura do ombro e antebraço do coelho, vista medial. 1 - Músculo serrátil ventral; 2 - Músculo subescapular; 3 - Músculo redondo maior; 4 - Músculo supraespinhoso; 5 - parte escapular do músculo deltoide; 6 - parte acromial do músculo deltoide; 7clavícula; 8 - cabeça longa do músculo tríceps braquial; 9 - cabeça acessória do músculo tríceps braquial; 10 cabeça medial do músculo tríceps braquial; 11 - músculo bíceps braquial. Adaptado de Popesko (1997).

O músculo infraespinhoso ( $M$. infraspinatus) ocupa a fossa infraespinhosa e se origina da região posterior da superfície lateral e da espinha da escápula. Insere-se no tubérculo maior do úmero (Bensley e Craigie, 1948; Cantier et al., 1968; Grumet et al., 2009). É relativamente estreito e, como o músculo supraespinhoso, segue até a superfície da cartilagem da escápula (Barone, 1989).

O músculo supraespinhoso ( $M$. supraspinatus) origina-se na porção anterior da face lateral da escápula (fossa supraespinhosa), na fáscia supraespinhosa e na fáscia subescapular (Figura 5). Insere-se no tubérculo maior do úmero (Bensley e Craigie, 1948; Cantier et al., 1968; Popesko, 1997; Grumet et al., 2009). Eventualmente, possui um ramo que segue para o tubérculo menor do úmero. É coberto pelo músculo subclávio (Barone, 1989).

O músculo subescapular (M. subscapularis) é relativamente estreito, ocupa completamente a fossa subescapular e insere-se no tubérculo menor do úmero. É revestido por uma forte fáscia em sua face medial (Bensley e Craigie, 1948; Cantier et al., 1968; Barone, 1989; Popesko, 1997; Grumet et al., 2009).

O músculo redondo maior ( $M$. teres major) é um músculo extenso que vai do ângulo caudal da escápula e da cartilagem escapular até o corpo do úmero, onde é fixado por um tendão que compartilha com o músculo grande dorsal (Figura 5) (Bensley e Craigie, 1948; Cantier et al., 1968; Popesko, 1997).

O músculo redondo menor ( $M$. teres minor) é estreito e curto, origina-se na porção ventral da margem caudal da escápula e insere-se no tubérculo maior do úmero. É intimamente associado ao músculo infraespinhoso, mas separado do músculo redondo maior por um tendão que tem origem da cabeça longa do tríceps (Bensley e Craigie, 1948; Barone, 1989; Grumet et al., 2009).

O músculo coracobraquial (M. coracobrachialis) é um pequeno músculo fusiforme que se origina no processo coracóide por um pequeno tendão, inclina-se sobre o tendão terminal do músculo subescapular e insere-se na porção distal do terço proximal do úmero, em sua face medial, próximo à tuberosidade redonda maior (Bensley e Craigie, 1948; Cantier et al., 1968; König e Liebich, 2016). Cobre a inserção dos músculos redondo maior e grande dorsal (Barone, 1989).

\section{Antebraço e braço}

O músculo bíceps braquial (M. biceps brachii) é alongado e cobre a face cranial do braço, que tem sua origem na borda cranial da cavidade glenóide, no tubérculo supraglenóideo da escápula. Liga a um tendão forte na região caudomedial do rádio na face medial do rádio, abaixo do cotovelo (Figura 5) (Crabb, 1931; Bensley e Craigie, 1948; Cantier et al., 1968; Barone, 1989; Schaller, 2007). 
Possui somente uma cabeça no coelho (Bensley e Craigie, 1948). A aponeurose desse músculo (Lacertus fibrosus) é larga e bem discernível (Barone, 1989).

O músculo braquial ( $M$. brachialis) é largo e forte e origina-se nas superfícies lateral e cranial do úmero, dividido em uma porção lateral maior e outra medial menor (Bensley e Craigie, 1948; Barone, 1989). O ponto de inserção é na porção caudomedial do rádio (Crabb, 1931; Bensley e Craigie, 1948; Schaller, 2007).

O músculo tensor da fáscia antebraquial $(M$. tensor fasciae antebrachii, antigo $M$. anconaeus quartus) origina-se na fáscia da superfície medial do úmero e tem como inserção um ponto na superfície medial do olecrano (Bensley e Craigie, 1948).

O músculo ancôneo ( $\mathrm{M}$. anconeus, antigo $\mathrm{M}$. anconaeus minimus) origina-se no epicôndilo medial do úmero e insere-se na superfície medial do olecrano. Faz parte do grupo de músculos extensores do braço (Bensley e Craigie, 1948).

O músculo tríceps braquial (Triceps brachii) possui quatro origens (Barone, 1989). A cabeça longa (Caput longum), na porção ventral da borda caudal da escápula, próxima à tuberosidade infraglenoidal e ao colo da escápula, é espessa e fusiforme (Figura 5) (Bensley e Craigie, 1948; Barone, 1989). A cabeça lateral (Caput laterale) é larga e possui sua metade distal cobrindo a cabeça longa; origina-se no tubérculo maior e porção adjacente da superfície lateral do úmero (Bensley e Craigie, 1948; Barone, 1989). A cabeça medial (Caput mediale) é quase tão longa quanto as duas anteriores, porém mais estreita, e originase na superfície caudal do úmero (Bensley e Craigie, 1948; Barone, 1989). A cabeça acessória (Caput acessorium) é muito pequena e inicia-se próximo ao colo do úmero (Barone, 1989). Todas inserem-se no olecrano e fazem parte do grupo de músculos extensores do braço. São quase músculos separados (Bensley e Craigie, 1948; Barone, 1989; Popesko, 1997).

O músculo braquiradial (M. brachioradialis), encontrado em cães e gatos (Popesko, 1997), é inexistente no coelho (Barone, 1989).

O músculo extensor carpo radial longo ( $M$. extensor carpi radialis longus) origina-se no epicôndilo lateral do úmero e insere-se na base do segundo metacarpiano (Bensley e Craigie, 1948). É parcialmente fusionado com o músculo extensor carpo radial curto, sendo considerado como músculo único por Barone (1989) e Popesko (1997).

O músculo extensor carpo radial curto ( $M$. extensor carpi radialis brevis) origina-se no epicôndilo lateral do úmero e, na base do terceiro metacarpiano, possui sua inserção. É parcialmente fusionado com o anterior, e os tendões são intimamente associados no pulso (Bensley e Craigie, 1948).

O músculo abdutor do primeiro dígito ( $M$. abdutor digiti I longus) origina-se na superfície craniolateral do rádio e da ulna e insere-se na base do primeiro metacarpiano (Figura 6). O músculo extensor digital comum ( $M$. extensor digitorum communis) parcialmente o esconde e seu tendão forma uma cruz notável com o do músculo extensor carpo radial longo e extensor carpo radial curto (Bensley e Craigie, 1948; Popesko, 1997).

O músculo extensor digital do primeiro dígito (M. extensor digiti I) tem sua origem nas superfícies craniolaterais do rádio e da ulna e insere-se no ápice da falange distal e na cabeça do segundo metacarpiano (Figura 6). Esse tendão é o primeiro de cinco no centro do carpo (Bensley e Craigie, 1948).

O músculo extensor digital comum (M. extensor digitorum communis) origina-se no epicôndilo lateral do úmero e extremidade proximal da ulna e insere-se, através de quatro tendões, em todas as quatro falanges laterais (II, III, IV e V) (Bensley e Craigie, 1948; König e Liebich, 2016).

O músculo extensor digital lateral ( $M$. extensor digitorum lateralis) é dividido em dois músculos paralelos: o músculo extensor digital IV próprio ( $M$. extensor digiti quarti proprius) e músculo extensor digital $\vee$ (antigo extensor digiti quinti proprius) (Barone, 1989). O músculo extensor digital IV próprio origina-se no epicôndilo umeral lateral e inserese na falange ungueal do quarto dígito (Bensley e Craigie, 1948). O músculo extensor digital V originase no epicôndilo lateral e superfície lateral da ulna. Insere-se na cabeça do quinto metacarpiano e base da primeira falange do quinto dígito (Bensley e Craigie, 1948). Ambos os músculos unem-se, próximo à extremidade distal de seus respectivos dígitos, aos ramos correspondentes do músculo extensor digital comum (Barone, 1989). 
O músculo extensor carpo ulnar (M. extensor carpi ulnaris, também chamado de $M$. ulnaris lateralis) é muito pequeno e origina-se no epicôndilo lateral do úmero e porção proximal da superfície lateral da ulna (Figura 6). Insere-se na base do quinto metacarpiano (Bensley e Craigie, 1948; Barone, 1989; König e Liebich, 2016).

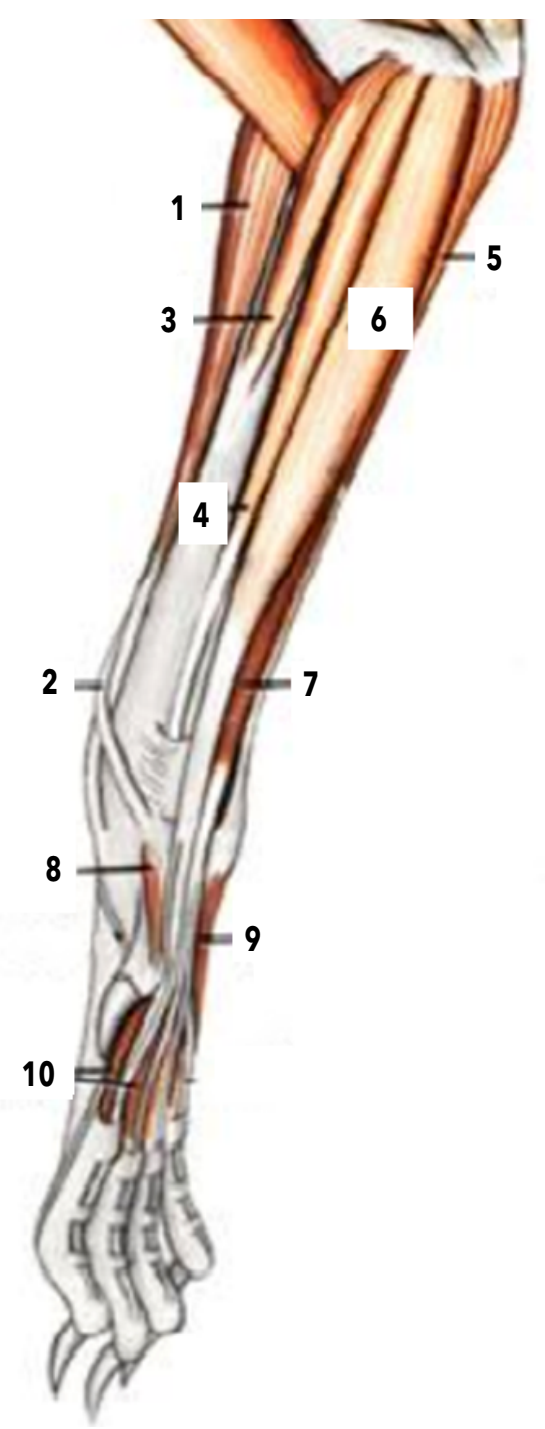

Figura 6 - Musculatura do braço do coelho, vista medial. 1- Músculo extensor carpo radial; 2- Músculo abdutor do primeiro dígito; 3 - Músculo pronador redondo; 4 Músculo flexor radial do carpo; 5 - Músculo flexor carpo ulnar; 6 - Músculo flexor digital profundo; 7 - Músculo flexor digital superficial; 8 - Músculo flexor curto do primeiro dígito; 9 - Músculo abdutor do $5^{\circ}$ dígito; 10 Músculos interósseos. Adaptado de Popesko, 1997.
O músculo pronador redondo ( $M$. pronator teres) é um músculo flexor muito fino, parcialmente fibroso, tem origem no epicôndilo medial do úmero e insere-se na superfície ventral do rádio (Bensley e Craigie, 1948; Barone, 1989; Popesko, 1997).

O músculo flexor radial do carpo ( $M$. flexor carpi radialis) é pequeno, origina-se no epicôndilo medial do úmero e insere-se na base do segundo metacarpiano (Figura 6) (Bensley e Craigie, 1948; Barone, 1989; Popesko, 1997).

Os músculos interflexores ( $\mathrm{Mm}$. interflexorii) originam-se no epicôndilo medial do úmero, em comum com a porção ulnar do músculo flexor digital profundo, e na porção proximal da ulna; inserem-se nas bases das falanges médias dos quatro dígitos laterais (Bensley e Craigie, 1948; König e Liebich, 2016).

O músculo flexor digital superficial (M. flexor digitorum superficialis, antigo M. palmaris) é um músculo flexor, tem origem no epicôndilo medial do úmero e insere-se superficialmente na face palmar do carpo (Figura 6) (Bensley e Craigie, 1948; Barone, 1989). Esse músculo delgado encontra-se entre a porção superficial do flexor digital profundo e o flexor carpo ulnar (Bensley e Craigie, 1948; Popesko, 1997).

O músculo flexor digital profundo (M. flexor digitorum profundus) possui quatro porções de origem: a superficial (Caput humerale, epicôndilo medial do úmero), a radial (Caput radiale, superfície caudal do rádio), a média (Lig. accessorium, superfície caudal da ulna) e a ulnar (Caput ulnare, epicôndilo medial do úmero, em comum com a porção superficial) (Figura 6). Inserem-se através de cinco tendões nas bases das falanges distais (Bensley e Craigie, 1948).

O músculo flexor carpo ulnar (M. flexor carpi ulnaris) origina-se no epicôndilo medial do úmero e na superfície medial do olécrano, formando duas curtas cabeças separadas (Caput humerale e Caput ulnare). Insere-se no carpo acessório (Figura 6) (Bensley e Craigie, 1948).

O músculo flexor digital $\vee(M$. flexor digiti $V$ ) origina-se no carpo acessório e no tendão do flexor digital profundo. Insere-se nos ossos sesamóides das articulações metacarpofalangeanas do quinto dígito, até a falange distal. É um pequeno músculo superficial à divisão mais lateral do tendão do 
flexor digital profundo (Bensley e Craigie, 1948; Barone, 1989).

Os músculos lumbricales (Mm. lumbricales) são três e originam-se do ponto de divisão do tendão flexor digital profundo. Inserem-se da face medial da falange proximal nos dígitos III, IV e V (Bensley e Craigie, 1948; Barone, 1989; Schaller, 2007).

Os músculos adutor digital V (M. adductor digit $V$ ) e adutor digital IV (M. adductor digiti IV) são músculos delgados que originam-se próximos ao tendão do flexor digital profundo e inserem-se, através de tendões finos, na superfície medial do quinto e quarto dígitos, respectivamente (Bensley e Craigie, 1948). O músculo adutor digital IV é descrito por Bensley e Craigie (1948), porém não é descrito na Nômima Anatômica Veterinária (ICVGAM, 2017).

Além do adutor digital $\mathrm{V}$ e do flexor digital $\mathrm{V}$, o quinto dígito possui o músculo abdutor digital $V(M$. abductor digiti V), que é pequeno e bem desenvolvido (Barone, 1989).

O músculo flexor curto do dígito I [M. flexor digiti I (pollicis) brevis] é muito pequeno e origina-se na superfície lateral do ligamento carpal transverso (Figura 6). Sua inserção é no lado abaxial da base da falange proximal do primeiro dígito (Bensley e Craigie, 1948; Barone, 1989; Popesko, 1997).

Não há músculos no dígito II em coelhos, além dos músculos interósseos (Barone, 1989).

Os músculos interósseos ( $\mathrm{Mm}$. interossei) são quatro e originam-se em pares a partir das bases do segundo ao quinto metacarpos e porções relativas aos ossos do carpo (Figura 6). Inserem-se nos ossos sesamóides das articulação metacarpofalangeanas (Bensley e Craigie, 1948; Barone, 1989).

O coelho não possui o músculo pronador quadrado (M. pronador quadratus) (Barone, 1989), que é um músculo observado em carnívoros (Dyce et al ., 2010).

\section{Vascularização e inervação do membro torácico}

A artéria axilar ( $A$. axillaris) provem da artéria subclávia, ramifica-se em ramos caudal e, frequentemente, cranial, antes de percorrer pelo braço como artéria braquial (Bensley e Craigie,
1948; König e Liebich, 2016). Dois ramos suprem os músculos da escápula: artéria subescapular (A. subescapularis) e artéria toracodorsal (A. thoracodorsalis) (Popesco, 1997). As artérias cincunflexas umeral caudal e cranial ( $A$. circumflexa humeri caudalis e $A$. circunflexa humeri cranialis) seguem da artéria subescapular e suprem o úmero e músculos adjacentes, e podem atravessar como um ou mais ramos, sendo que o maior (caudal) passa entre os músculos coracobraquial e redondos, levando ramos ao deltóide e à extremidade proximal das cabeças lateral e longa do tríceps. Ela continua (ramo descendente) na face lateral da cabeça medial do tríceps e passa para a cabeça lateral do braquial, próximo ao cotovelo, como artéria radial colateral (A. collateralis radialis) (Bensley e Craigie, 1948; Neyret, 1979; König e Liebich, 2016). Um ramo da artéria colateral radial atinge a superfície do músculo extensor radial do carpo, onde se anastomosa com o ramo ascendente da artéria radial proximal ( $A$. antebrachialis superficialis cranialis), que equivale à artéria anterobraquial superficial cranial de outros mamíferos (Neyret, 1979). A artéria ulnar transversa ( $A$. transversa cubiti) origina-se no nível do ângulo do cotovelo, passando entre o úmero e os músculos bíceps braquial e braquial, dividindose em dois ramos: ascendente, que irriga parte do músculo braquial, e descendente, ao longo do nervo radial, em anastomose com um ramo descendente da artéria circunflexa caudal do úmero (Neyret, 1979). O ramo descendente segue para a face profunda do músculo anterobraquial dorsal, sendo próximo ao ramo profundo do nervo radial (Neyret, 1979).

A parte distal de distribuição desse vaso corresponde à parte distal profunda ou artéria superior profunda do ser humano. A artéria profunda (A. profunda brachii) do coelho é pequena e origina-se do início da artéria braquial (Bensley e Craigie, 1948). É comumente representada por três ou quatro ramos na margem caudal dos nervos radial, médio e ulnar, acompanhando o primeiro por uma curta distância, e supre o músculo tríceps braquial (Bensley e Craigie, 1948; Neyret, 1979).

A artéria braquial ( $A$. brachialis), continuação da artéria axilar, passa próxima à porção final da superfície medial do braço, entre o bíceps braquial 
e a cabeça medial do tríceps. Atravessando a superfície cranial de sua extremidade distal, ele passa sob a cabeça do músculo pronador redondo à superfície medial do rádio, dividindo-se nesse ponto (a uma curta distância do cotovelo) em artérias média e ulnar (Bensley e Craigie, 1948). Seus ramos principais no braço são as artérias colaterais ulnar (superior, média e inferior), que servem aos músculos e articulação do cotovelo. A artéria colateral ulnar (A. collateralis ulnaris) acompanha o nervo ulnar para irrigar os músculos que iniciam ou terminam no olécrano (Bensley e Craigie, 1948; Neyret, 1979). Ela termina no ramo interósseo, o qual segue entre o rádio e a ulna. $A$ artéria interóssea comum ( $A$. interossea communis) segue abaixo da articulação do cotovelo e dirigese para o espaço interósseo, no qual divide-se em artéria cranial ( $A$. interossea cranialis) e caudal ( $A$. interossea caudalis), que anastomosa com o ramo carpal da artéria radial (Bensley e Craigie, 1948; Neyret, 1979). A artéria bicipital (A. bicipitalis) é composta por duas artérias, uma proximal e outra distal, que irrigam o músculo bíceps braquial (Neyret, 1979). A artéria nutrícia do úmero (A. nutricia humeri) está relacionada à artéria braquial (Neyret, 1979).

A artéria mediana ( $A$. mediana) passa ao final da borda caudomedial do rádio, juntamente com o nervo mediano, situado entre o flexor carpo radial e a porção radial do flexor digital profundo (Bensley e Craigie, 1948; König e Liebich, 2016). É uma prolongação da artéria braquial, após a artéria interóssea comum. Seu curso e relações são iguais às descritas em outras espécies de mamíferos domésticos (Neyret, 1979). Seus colaterais são a artéria profunda do antebraço ( $A$. profunda antebrachii) e a artéria radial (A. radialis). Uma pequena artéria radial pode ser vista antes da bifurcação entre as artérias mediana e ulnar, e pode correr superficialmente ao final do antebraço (Bensley e Craigie, 1948). A artéria radial corre cranialmente ao longo da artéria mediana e termina no nível do carpo em dois ramos: ramos carpal dorsal (ramus carpeus dorsalis), que forma a rede dorsal do carpo com o descendente da artéria radial, e o ramo carpal palmar (ramus carpeus palmaris), que ajuda a formar o arco palmar profundo (Neyret, 1979). Em direção à extremidade distal do rádio, a artéria mediana cruza a superfície caudal do tendão do flexor carpo radial e aparece em uma posição superficial na borda medial do carpo (Bensley e Craigie, 1948). Ela contribui para a formação de um arco palmar superficial, onde originam as artérias digitais palmares comuns (Bensley e Craigie, 1948; Neyret, 1979).

A artéria superficial cranial do antebraço ( $A$. antebrachialis superficialis cranialis), antigamente conhecida como radial proximal, separa-se da borda cranial da artéria interóssea comum e cruza obliquamente a superfície cranial do rádio, passando sob a artéria mediana e atingindo a região cranial do antebraço. Divide-se em dois ramos: 0 ascendente, que anastomosa com a artéria braquial superficial (A. brachialis superficialis) ao longo da veia cefálica e ramo superficial do nervo radial, e o descendente, que distribui-se aos músculos antebraquiais craniais e une-se ao ramo carpal dorsal da artéria radial, reforçado pela artéria interóssea caudal, para formar a rede de irrigação do carpo (Neyret, 1979).

A artéria ulnar ( $A$. ulnaris) atravessa a ulna obliquamente desde sua origem, alcançando dessa forma a borda lateral do flexor ulnar do carpo, através do qual ela passa até o fim do antebraço e ao lado ulnar do osso carpo acessório. Ela passa para a superfície palmar do quinto dígito e então forma o arco palmar (Bensley e Craigie, 1948).

A maior parte das veias dos membros torácicos acompanha o trajeto das artérias, recebendo o mesmo nome, como as veias subescapular ( $V$. subescapularis), toracodorsal (V. thoracodorsalis) e colateral ulnar ( $V$. collateralis ulnaris) (Popesko, 1997; König e Liebich, 2016). Uma única veia braquial ( $V$. brachialis) acompanha a artéria braquial. É formada cranialmente ao cotovelo pela união de duas veias, a mediana ( $V$. mediana) e a ulnar ( $V$. ulnar), as quais acompanham as artérias correspondentes e se unem no ponto de separação de ambas. A veia mediana anastomosa com a porção radial da cefálica no ponto distal do meio do antebraço (Bensley e Craigie, 1948).

$A$ veia cefálica ( $V$. cephalica) é um grande vaso superficial que aparece na superfície cranial do antebraço. Na face medial do antebraço recebe um grande afluente que anastomosa com a veia mediana. É acompanhado pelo ramo superficial do 
nervo radial, passa na face cranial do braço e através do ângulo do cotovelo, encontra-se primeiramente na margem cranial da cabeça lateral do músculo braquial e depois na superfície lateral do braço, entre a porção acromial do deltoide e a cabeça lateral do tríceps. Ele desaparece dessa superfície no espaço triangular delimitado por esses músculos e a inserção do elevador da escápula maior, recebendo nesse ponto um grande afluente do ombro. Ainda, aparece na superfície medial do ombro na porção distal final da borda axilar da escápula, entre o redondo maior e o subescapular, entrando na veia axilar aproximadamente no mesmo lugar que a veia subescapular (Bensley e Craigie, 1948).

O plexo braquial do coelho é formado pelos ramos ventrais do quinto nervo espinhal cervical (C5), sexto nervo espinhal cervical (C6), sétimo nervo espinhal cervical (C7), oitavo nervo espinhal cervical (C8), primeiro nervo espinhal torácico (Th1) e ramo caudal do segundo nervo espinhal torácico (Th2). O ramo caudal do $\mathrm{C} 5$ e $\mathrm{C} 6$ constituem o tronco cranial. O tronco caudal é formado por um braço originado no tronco cranial e os ramos ventrais do C7, C8 e Th1. O tronco cranial divide-se em nervo frênico ( $N$. phrenicus) e nervo supraescapular ( $N$. supraescapularis). O tronco caudal divide-se em nervo peitoral cranial (Nn. pectorales craniales) e nervo axilar ( $N$. axillaris). O nervo supraescapular origina-se nos nervos espinhais de $\mathrm{C} 5$ e C6. O nervo musculocutâneo ( $N$. musculocutaneus) deriva de $\mathrm{C} 6$ e $\mathrm{C} 7$ e segue até o bíceps, suprindo a pele do antebraço. O nervo cutâneo medial ( $N$. cutaneus antebrachii medialis) segue para a pele do antebraço (Reichert et al., 2014).

O nervo axilar ( $N$. axillaris) começa de C7 e supre os músculos deltóides (Figura 7) (Reichert et al., 2014). Divide-se em dois ramos. O primeiro (Rami musculares) supre os músculos subescapular e redondo maior. Ao nível do colo da escápula, na face caudal, passa entre os músculos redondo maior e supraescapular até a face lateral da escápula. Depois de fornecer ramos para os músculos redondo menor e deltóide, passa para a face lateral do membro torácico através do espaço entre a cabeça lateral do tríceps braquial e deltóide e forma o ramo cutâneo lateral cranial ( $N$. cutaneus brachii lateralis cranialis), que se espalha para a região cranial e lateral do membro torácico e continua como nervo cutâneo cranial do antebraço ( $N$. cutaneus antebrachii cranialis) (Mussa et al., 2016).

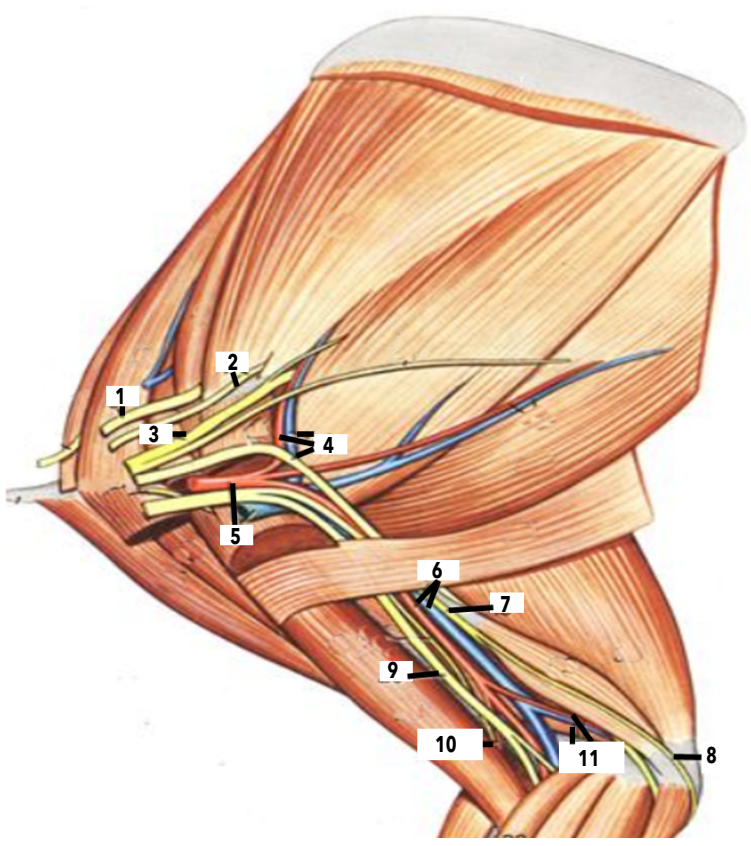

Figura 7 - Artérias, veias e nervos da superfície medial ombro e antebraço do coelho. 1- Nervo supraescapular; 2 - Nervo subescapular; 3 - Nervo axilar; 4 - Artéria e veia subescapulares e nervo radial; 5 - Artéria e veia axilares; 6 - Artéria. e veia braquiais; 7- Nervo ulnar; 8- Nervo nervo cutâneo lateral do antebraço; 9 - Nervo mediano; 10 - Artéria ulnar transversa; 11 - Artéria e veia colaterais ulnares. Adaptado de Popesko (1997).

O nervo radial ( $N$. radial) origina-se do $\mathrm{C} 7, \mathrm{C} 8$ e Th1, e inerva o músculo tríceps (Reichert et al., 2014). Próximo ao terço médio do úmero, passa entre as cabeças medial e lateral do músculo tríceps braquial até a face lateral do braço. Determina ramificações (Rami musculares) para os músculos tensor da fáscia do antebraço e tríceps braquial. Primeiro fornece o nervo cutâneo lateral do antebraço ( $N$. cutaneus brachii lateralis caudalis) entre o músculo braquial e a cabeça lateral do músculo tríceps braquial, dividindo-se, em seguida, em dois ramos: ramo profundo (Ramus profundus) e ramo superficial (Ramus superficialis). 
O primeiro distribui-se através dos músculos extensores do antebraço (Rami musculares). O ramo superficial separa-se em nervos digital dorsal comum (Nn. digitales dorsales communes) II e IV na região distal do antebraço, descendo ao músculo extensor carpo radial (Bensley e Craigie, 1948; Mussa et al., 2016).

O nervo mediano ( $N$. medianus) vem dos nervos espinhais $\mathrm{C} 7, \mathrm{C} 8$, Th1 e passa ao longo da superfície medial do braço, ficando inicialmente à frente da artéria braquial e depois no seu lado medial (Figura 7). Acompanha a artéria braquial, passando por baixo da cabeça do pronador redondo e, em seguida, atravessa o antebraço, em companhia da artéria radial, até a superfície palmar da mão (Bensley e Craigie, 1948; Reichert et al., 2014). Forma dois ramos na altura da articulação do cotovelo, chamados de ramo muscular (Rami musculares) e nervo interosseo antebraquial ( $N$. interosseus antbrachii). Eles terminam em quatro ramos: nervos digital palmar comum ( $N$. digitalis palmaris communes) I, II, III e IV, no nível central da face palmar do metacarpo (Mussa et al., 2016).

$\mathrm{O}$ nervo ulnar ( $N$. ulnaris) provém do $\mathrm{C} 8 \mathrm{e}$ Th1 e supre a região distal ao cotovelo (Reichert et al., 2014). O nervo ulnar torna-se caudal à artéria braquial. Em direção à extremidade distal do úmero, acompanha a artéria colateral ulnar inferior. Atravessa a face medial do cotovelo até a face dorsal da cabeça do olécrano e do flexor ulnar do carpo e, então, cruza a ulna obliquamente, juntamente da artéria ulnar, até a borda lateral do músculo e ao longo dele para o tendão de inserção. No punho, ele cruza a superfície dorsal do tendão e atinge a superfície palmar da mão (Bensley e Craigie, 1948). Divide-se em nervo digital dorsal (N. digitalis dorsalis proprius) e palmar (N. digitalis palmaris proprius) na face caudomedial do antebraço. Possui um ramo que inerva os tecidos do subcutâneo da região palmar (Nn. metacarpei palmares) (Mussa et al., 2016).

\section{Conclusão}

Pesquisas médicas e avaliações anatômicas em pacientes com processos patológicos que necessitem de uma descrição detalhada sobre a anatomia do membro torácico do coelho, podem sofrer com a falta ou dificuldade na obtenção dessa informação. Com a evolução dos métodos de imagem diagnóstica, as estruturas estudadas podem ser observadas com maior detalhamento, permitindo uma descrição mais acurada das características anatômicas e contribuindo para melhor entendimento do estado e do prognóstico do paciente. O mesmo pode ser observado nas pesquisas que envolvem esta espécie, cujos métodos de obtenção de dados podem exigir maior detalhamento anatômico. Fazem-se necessários novos estudos com disponibilização de material descritivo e visual para auxiliar na compreensão da anatomia, bem como textos em língua portuguesa para facilitar o acesso dos profissionais à informação. Para eficiência na comunicação entre o público-alvo, ou seja, relacionado ao coelho (Oryctolagus cuniculus) como objeto de estudo e pesquisa, é importante a atualização e padronização da nomenclatura.

\section{Agradecimentos}

O presente trabalho foi realizado com apoio da Coordenação de Aperfeiçoamento de Pessoal de Nível Superior (CAPES) - Código de Financiamento 001.

\section{Referências}

Barone R. Anatomie comparée des mammiferes domestiques. Tomo 1: Ostéologie. Paris: Vigot Freres; $1986.762 \mathrm{p}$.

Barone R. Anatomie comparée des mammiferes domestiques. Tomo 2: Arthrologie et myologie. Paris: Vigot; $1989.984 \mathrm{p}$.

Baumann AP, Aref MW, Turnbull TL, Robling AG, Niebur $\mathrm{GL}$, Allen MR, et al. Development of an in vivo rabbit ulnar loading model. Bone. 2015;75:55-61.

Bensley BA, Craigie EH. Bensley's practical anatomy of the rabbit: an elementar laboratory text-book in mammalian anatomy. 7 ed. Philadelphia: Blakiston; 1948. 416 p. 
Burkholder TH, Linton G, Jr RFH, Young R. The rabbit as an experimental model. In: Suckow MA, Stevens KA, Wilson RP. The laboratory rabbit, guinea pig, hamster and other rodents. San Diego: Elsevier; 2012. p. 52960.

Buettmann EG, Silva MJ. Development of an in vivo bone fatigue damage model using axial compression of the rabbit forelimb. J Biomech. 2016;49(14):3564-9.

Callou C. Diagnose différentielle des principaux éléments aquelettiques du lapin (genre oryctolagus) et du lièvre (genre lepus) en Europe occidentale. Juan-lesPins: Centre de Recherche Archéologiques du CNRS; 1997. $21 \mathrm{p}$.

Cantier J, Vezinhet A, Bouthier E, Bressot C, Goussopoulos J. Guide pour la dissection et l'identificalion des principaux muscles de la carcasse chez le lapin. Ann Biol Anim Bioch Biophys. 1968;8(1):107-39.

Crabb ED. Principles of functional anatomy of the rabbit. Philadelphia: Blakistion's Son \& Co; $1931.156 \mathrm{p}$

Doschak MR, Matyas JR, Hart DA, Bray RC. Vascular alterations in the rabbit patellar tendon after surgical incision. J Anat. 2001;198(Pt 5):513-23.

Dyce KM, Sack WO, Wensing CJG. Tratado de anatomia veterinária. 4 ed. Rio de Janeiro: Elsevier; 2010. 1714 p.

Grumet RC, Hadley S, Diltz MV, Lee TQ, Gupta R. Development of a new model for rotator cuff pathology: the rabbit subscapularis muscle. Acta Orthop. 2009;80 (1):97-103

ICVGAM - International comittee on veterinary gross anatomical nomenclature. Nomina anatomica veterinaria. 6 ed. Hanover: World Association of Veterinary Anatomists; 2017. 178 p.

König HE, Liebich HG. Anatomia dos animais domésticos: texto e atlas colorido. 6 ed. Porto Alegre: Artmed; 2016. $804 \mathrm{p}$.

Krause W. Die anatomie des kaninchens in topographischer und operative rucksicht.Leipzig: Verlag von Wilhelm Engelmann; 1868. 293 p.
Lebas F, Coudert P, Rochambeau H, Thébault RG. The rabbit: husbandry, health and production. Roma: FAO; 1997. $235 \mathrm{p}$.

Machado LC. Pesquisas de preferência, divulgação da atividade de cunicultura e mercado pet cunícula brasileiro. Rev Bras Cunicult. 2015;8(1):1-12.

Mussa T, Bhowmik S, Ali L, Islam A, Quasem A, Jalil A, et al. Origin and distribution of brachial plexus of White New Zealand rabbit (Oryctolagus cuniculus). Mal J Vet Res. 2016;7(1):53-64.

Neyret JP. Sur l'anatomie comparée des artères de l'avantbras chez les mammifères domestiques. I. Le système des artères radiales. Anat Histol Embryol. 1979;8(4):340-59.

Popesko P. Atlas de anatomia topográfica dos animais domésticos. 3 ed. São Paulo: Manole; 1997. 609 p.

Reichert P, Rutowski R, Kiełbowicz Z, Kuryszko J, Kiełbowicz M, Michalak $\measuredangle$, et al. The rabbit brachial plexus as an experimental model - anatomy and surgical approach. Pol J Vet Sci. 2014;17(2):339-45.

Sandstrom CJ, Saltzman A. A comparative study of the clavicular ligaments of the rat, rabbit, cat, and dog. Anat Rec. 1944;89(1):23-32.

Schaller O. Illustrated veterinary anatomical nomenclature. 2 ed. Stuttgart: Enke; 2007. 628 p.

Silverman S, Tell LA. Radiology of rodents, rabbits and ferrets: an atlas of normal anatomy and positioning. 1 ed. Missouri: Elsevier; 2005. 303 p.

Sohn J, Couto MA. Rabbits. Anatomy, physiology, and behavior. In: Suckow MA, Stevens KA, Wilson RP (Eds).

The Laboratory Rabbit, Guinea Pig, Hamster, and Other Rodents. St. Louis: Elsevier; 2012. p. 195-215.

Varga M. Textbook of rabbit medicine. 2 ed. Londres: Elsevier; 2014.512 p.

Whitehouse RH, Grove AJ. The dissection of the rabbit, with an appendix on the rat. 5 ed. Londres: University Tutorial Press Limited; 1956. 184 p. 